$$
\text { ¿CNF-890802...34 }
$$

\title{
STATUS REPORT ON THE ADVANCED PHOTON SOURCE PROJECT AT ARGONNE NATIONAL LABORATORY
}

Russell H. Huebner, Sr.

Argonne National Laboratory, Argonne, IL 60439

\section{ABSTRACT}

The Advanced Photon Source at Argonne National Laboratory is designed as a

$i=$

$F_{L}$ national synchrotron radiation user facility which will provide extremely bright. highly energetic $x$-rays for multidisciplinary research. When operational, the Advanced Photon Source will accelerate positrons to a nominal energy of $7 \mathrm{GeV}$. The positrons will be manipulated by insertion devices to produce $\mathrm{x}$-rays 10.000 times brighter than any currently available for research. Accelerator components. insertion devices, optical elements, and optical-element cooling schemes have been and continue to be the subjects of intensive research and development. A call for Letters of Intent from prospective users of the Advanced Photon Source has resulted in a substantial response from industrial. university, and national laboratory researchers.

\section{INTRODLCTION}

The Advanced Photon Source (APS) at Argonne National Laboratory will be a national user facility for synchrotron-radiation researchers from industry. universities, and national laboratories. In fact, the APS user community has been an important source of guidance and expertise throughout the project's planning.

By providing $x$-ray beams more brilliant than those currently available, the APS promises to play a substantial role in any discipline where knowledge of the structure of matter is important, from basic research in materials sciences. pharmaceutical research, atomic and molecular physics. chemistry and biology, and medical applications. The research being carried out today at existing synchrotronradiation facilities and the science being proposed for the APS underlie virtually all modern technologies.

\section{HISTORY}

In 1986, a conceptual design report ${ }^{1}$ (CDR) spearheaded by Dr. Yanglai Cho outlined plans for a $6-\mathrm{GeV}$ synchrotron radiation source to be built at ANL. A Department of Energy (DOE) Design Review Committee, in its otherwise favorable evaluation of the $6-\mathrm{GeV}$ machine, recommended further consideration of the storage-ring energy. A National Task Group was formed to reconsider the photon energy tunability of undulator beams in light of user needs ${ }^{2}$. That group settled on two principle recommendations: first, that an undulator at the new machine should 
provide fundamental radiation tunable over the $7-$ to $14-\mathrm{keV}$ range for the initial phase of operation, and second, that at mature operation. the minimum gap and the ring energy should allow the first undulator to be tunable over the $4.7-$ to $14-\mathrm{keV}$ interval, with $20-\mathrm{keV}$ radiation from at least the fundamental of a second undulator. In order to meet those criteria, the 1987 "Conceptual Design Report for the 7-GeV Advanced Photon Source" 3 upgraded the storage-ring energy to nominal operation at $7 \mathrm{GeV}$ with the capability to reach $\sim 7.7 \mathrm{GeV}$. On June 4,1990 , formal ground breaking ceremonies signaled the beginning of APS construction.

\section{RESEARCH OPPORTUNITIES AT THE APS}

Synchrotrons can be designed to generate radiation in almost any useful part of the electromagnetic spectrum. The APS will specialize in producing high-enicrgy $x$ rays up to about $200 \mathrm{keV}$ for materials research, condensed matter physics, chemistry, and biological and medical research. Potential results anticipated in science and technology are of major significance. The APS will:

- Open avenues to discovering and understanding novel phenomena in condensed matter - such as high-temperature super-conductivity - by providing new capabilities for static and dynamic (live action) determinations of structures.

- Extend our ability to study matter in very small samples. which is crucial to developing high-density circuits and computer memories and to understanding catalysts, metal clusters, and geological microstructures. The investigation of samples hundreds of times smaller than can be studied using existing $x$-ray sources will lead to more efficient industrial processes (petroleum cracking, for instance).

Provide new techniques for studying solid surfaces and liquids, for applications such as lubrication and layered thin films.

- Enhance our ability to examine the synthesis, structure, and properties of old and new materials, including ceramics and polymers. The APS will be a powerful tool in the burgeoning field of "designer materials" tailored at the atomic and molecular levels for specific applications.

- Offer unprecedented sensitivity for identifying intermediate stages in chemical reactions, a vital advantage for studying rapid processes such as combustion. Observation of the reactions that go on in coal combustion, for instance, may lead to cleaner ways to burn it.

- Open the door to rapid analysis of biomolecular structures, such as viruses and proteins, and examination of physiological structures and functions. With its unique ability to image reactions taking place in billionths of a second, the APS will revolutionize techniques in bioengineering.

- Perrit nondestructive studies of complex polymer structures, defects in semiconductors. and structural changes in steel during heat 
treatment. These studies will pay off in new materials for plastics, computing, and other high-tech industries.

Because there has never been an $x$-ray source this powerful for basic research, it seems certain these benefits will be supplemented by applications no one can yet imagine.

\section{TECHNICAL DESCRIPTION}

A schematic of the APS accelerator storage ring complex is shown in Fig. 1. The injection system consists of an electron/positron linear accelerator system, a positron accumulator ring (PAR), and a booster synchrotron. This system injects positrons at the full $7-\mathrm{GeV}$ energy into the storage ring. Operation of the accelerator is detailed as follows.

The APS will accelerate electrons from the electron gun (A) to $200 \mathrm{MeV}$ at a $60-\mathrm{Hz}$ rate along the first one-third of the linac (B). Focused to a 3-mm-diameter spot on a $7-\mathrm{mm}$-thick tungsten positron-production target $(\mathrm{C})$, the $200-\mathrm{MeV}$ electrons will yield 0.0083 positrons per incident electron within a solid angle of $0.15 \mathrm{sr}$ in the energy range of $8 \pm 1.5 \mathrm{MeV}$. A high-field pulsed solenoid will focus the positrons, which are then accelerated to $450 \mathrm{MeV}$ by the positron linear accelerator (D) over the remaining two-thirds of the linac's total 40-m length. Upon injection into the $30-\mathrm{m}$-circumference, $450-\mathrm{MeV}$ positron accumulator ring $(E)$, as many as 24 successive pulses or $3.6 \times 10^{10}$ positrons from the linac will be accumulated as a single bunch each 0.5 -second period. Bunch : - ngth compression in the PAR makes the beam more compact and allows pulses from the linac to be accumulated as the booster synchrotron is ramping-up the previous set of pulses. After injection into the $367-\mathrm{m}$-circumference booster/injector synchrotron ( $F$ ), positrons will be ramped-up from $450 \mathrm{MeV}$ to $7 \mathrm{GeV}$ in approximately one-third of a second. Because it cycles back down to $450 \mathrm{MeV}$ in order to pick up the next pulse, the booster performs two cycles per second, making it a $2-\mathrm{Hz}$ machine.

The storage ring $(G)$, with a circumference of 1104 meters, is designed for a nominal energy of $7 \mathrm{GeV}$, with the capacity to achieve $8-1 / 2 \mathrm{GeV}$. Under normal operating conditions, about 30 of the 1296 available of buckets will be filled with positron bunches carrying on the order of 5 milliamps each. Anticipated filling time is one minute.

The APS storage ring will have 40 sectors that each include a straight section. Rf cavities and injection apparatus will take up six of the straight sections, so there will be 34 usable sectors. Each sector will contain two bending magnets, with one of the bending magnets available to extract radiation, and one insertion device (ID), either a wiggler (for very intense $x$-rays over a wide band of energies) or an undulator (for radiation of selected energy at hirh spectral brilliance in the range between $10^{18}$ and $10^{19} \mathrm{ph} / \mathrm{s} / 0.1 \% \mathrm{BW} / \mathrm{mrad}^{2} / \mathrm{mm}^{2}$ ). That brilliance as calculated and displayed in Fig. 2 represents an increase of 3 or 4 orders of magnitude over what is now available from, for instance, bending magnets at the National 


\section{$\therefore$,}

A. ELECTRON GUN

B. ELECTRON LINEAR ACCELERATOR*

C. POSITRON CONVERSION TARGET

D. POSITRON LINE.AR ACCELERATOR•

E. POSITRON ACCUMULATOR RING

F. BOOSTERINJECTOR SYNCHROTRON

G. STORAGERING

H. INSERTION DEVICE

- Componens oi the linac system

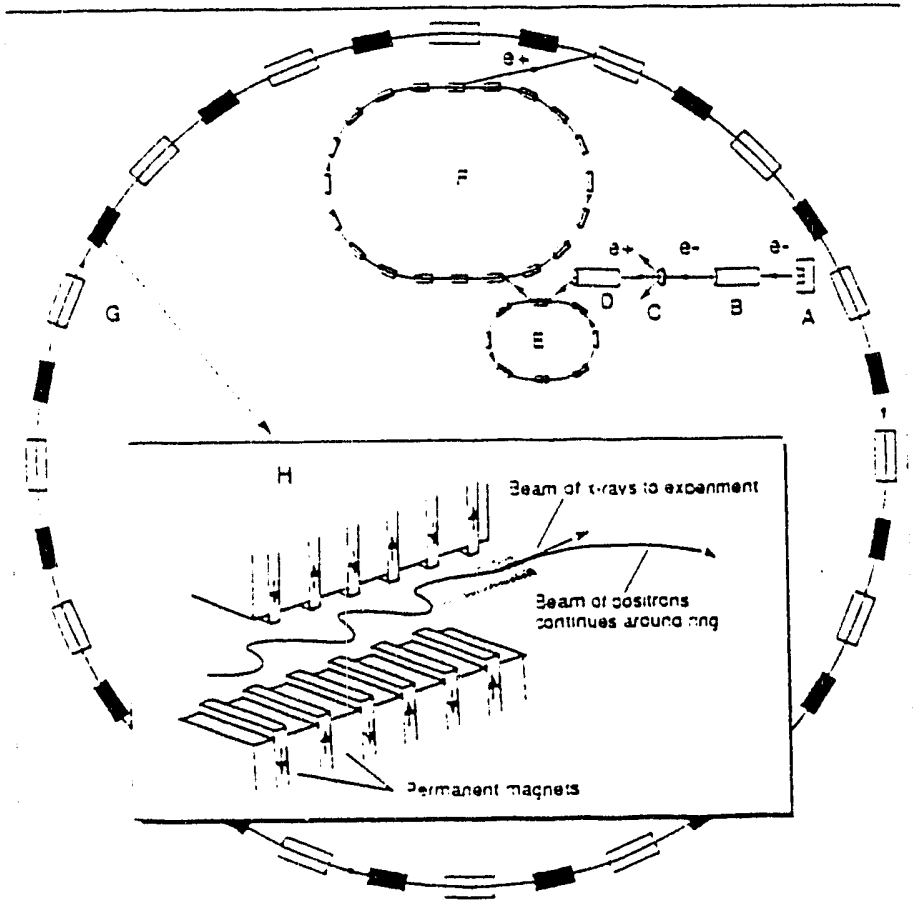

NOTE: Dlagramis not :o scale

Fig. 1. Diagrams of the Advanced Photon Source accelerator system and (inset) an insertion device.

\section{DISCLAIMER}

This report was prepared as an account of work sponsored by an agency of the United States Government. Neither the United States Government nor any agency thereof, nor any of their employees, makes any warranty, express or implied, or assumes any legal liability or responsibility for the accuracy, completeness, or usefulness of any information, apparatus, product, or process disclosed, or represents that its use would not infringe privately owned rights. Reference herein to any specific commercial product, process, or service by trade name, trademark, manufacturer, or otherwise does not necessarily constitute or imply its endorsement, recommendation, or favoring by the United States Government or any agency thereof. The views and opinions of authors expressed herein do not necessarily state or reflect those of the United States Government or any agency thereof. 


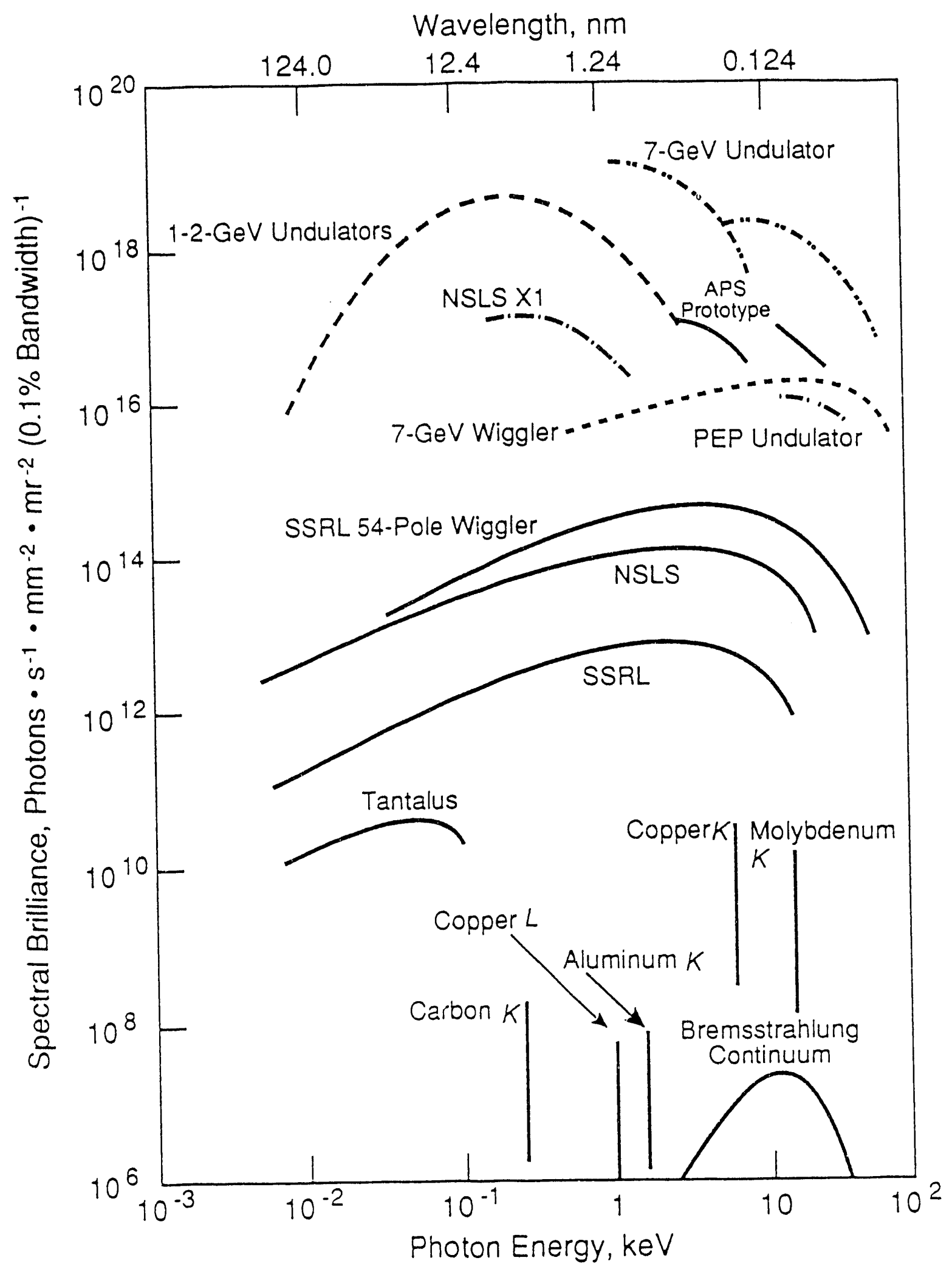

Fig. 2. Brilliance as a function of photon energy for synchrotron radiation sources, operating and under development. 
Synchrotron Light Source. The IDs, essential to optimization of the beams provided by the APS, have been, and continue to be, a primary R\&D focus.

Due in no small part to the materials science community's early involvement in the overall facility design ${ }^{4}$, the APS will provide considerable space for research. User modules containing two labs of several hundred square feet each, as well as offices, are planned for each sector of the machine.

\section{R\&D STATUS}

\section{Accelerator physics}

Anticipating the behavior of particles in a storage ring is among the most daunting of accelerator-physics issues. The APS Accelerator Systems Division is performing a series of experiments ${ }^{5}$ using the Aladdin storage ring at the Synchrotron Radiation Center in Wisconsin. These experiments serve as a check on computer programs that must predict the behavior of particle dynamics in the APS storage ring, as measured in response to perturbations. Under experimental conditions. APS simulations have proven to be very accurate. The measurements also resulted in specific determinations about the operational parameters of the magnets in the Aladdin ring, conditions which were not known at that level of detail at that time. making this undertaking useful for scientists at Aladdin as well as at APS.

\section{Vacuum chambers}

There will be 240 standard-design sections of vacuum chamber, each approximately 15 feet long, in the storage ring alone. Forty specially designed narrow vacuum chamber sections will also be required for the straight sections of the storage ring. Five prototype storage ring vacuum-chamber segments, complete with all welds, hardware, and ports, have been constructed and are being tested by the Accelerator Systems Division. Fabrication of these chambers requires intricate welding to allow connection of all segments in the ring. A totally computerautomated welding procedure has resulted from the R\&D effort carried out with Ferranti Sciaky, Inc., of Chicago.

Configuring two of the vacuum chamber segments in each sector to match bending-magnet curvature of 4.5 degrees nas not been a trivial matter. It was realized that if the chambers could not be bent, they would have to be machined rather than extruded, a much more expensive altemative. A method for bending the chambers, the subject of an $R \& D$ initiative begun several years ago together with Pacific Pipe of Oakland. California, has been successfully demonstrated, putting to rest a key technical and budget issue.

Aluminum and aluminum alloys are finding a place as the preferred material for the demanding task of producing the ultrahigh-vacuum systems in particle-beam accelerators. Salient characteristics of the material required for this application include machinability, good thermal conductivity, tolerance for localized high heat flux, low thermal emissivity, low outgassing rate and residual radioactivity. long 
radiation length, low energy loss, and non-magnetism. These characteristics are exhibited by aluminum and aluminum alloys. In addition. the formability of aluminum is very good, thus permitting the accurate bending of a chamber section about its hard axis to the radius of the synchrotron's storage-ring bending magnets.

In the particular case of the APS, the 6063T5 alloy was selected for the more than 240 chambers that will be maintained at a vacuum of $10^{-11}$ Torr during operation. 6063T5 was chosen for its extrudability, and because it will provide the excellent structural and thermal properties necessary for vacuum chamber fabrication. The weldability of the $6063 \mathrm{~T} 5$ aluminum relative to the 2219 aluminum alloy employed for the balance of the chamber is very good.

\section{Magnets}

The design of all APS magnets has been optimized for operation at levels corresponding to $7 \mathrm{GeV}$. Magnet geometries are defined to fit associated vacuum chambers with required clearances between magnet and chamber. Magnets will accommodate installation of associated vacuum chambers after magnet assembly and measurement. Most of the APS magnets are designed for low-carbon steel laminations and copper conductor. APS magnets are being designed in-house, with components (cores, coils, and manifolds) to be manufactured by industry and assembled at ANL. At least one prototype of each magnet will be built at ANL to validate the design of the core assembly tooling and to develop assembly procedures for core and magnet. Pole-face and coil geometries are being defined with the aid of computer programs in two dimensions. The shape of ends of poles will be defined. as required, with computer programs in three dimensions and through prototyping.

As there will be a total of 1503 magnets of various types in the APS accelerator complex, R\&D in this a:ea is crucially important. The first prototype of 400 APS storage-ring quadrupole (SRQ) magnets has been assembled from components fabricated to APS specifications. The SRQ, though a straightforward electromagnet. is very demanding in terms of magnetic-field quality: requiring field gradients accurate to 1 part in $10^{4}$. Critical parameters must also be achieved economically over the entire SRQ fabrication cycle. as they must for all APS magnets.

The prototype 0.8-m-long SRQ was transported to Fermi National Accelerator Laboratory for magnetic measurements, which proved to be with in the required margin of error. Slight design modifications are now under way prior to assembly and testing of a second SRQ. In order to expedite the measurement process, an APS magnet-measurement facility is scheduled to be on line at Argonne in the summer of 1990.

Insertion devices

$A$ collaboration between the APS Experimental Facilities Division and researchers at Comell University resulted in the design of a new insertion device, the APS/CHESS undulator (Type A). APS staff then worked with Spectra Technology of Bellevue, Washington, to construct the 3.1-cm-period device. In 1988, the prototype APS/CHESS undulator was installed at the Comell Electron Storage Ring. 
CESR, where it performed according to design calculations ${ }^{6}$. The tunability of firstharmonic $x$-rays measured for this device is shown in Fig. 3.

A new $7.5-\mathrm{cm}$ undulator ${ }^{7}$ has now been constructed (see Fig. 4) and is being tested at the U-5 port of the vacuum ultraviolet ring at the National Synchrotron Light Source, Brookhaven National Laboratory. Currently under consideration is a wiggler device to produce circularly polarized radiation, an advance certain to be of interest to the atomic physics community. The parameters planned for general purpose insertion devices to be developed for use at the APS are summarized in Table I.

\section{Optics}

The problem of thermal loading on beamline optical components is also the subject of active study ${ }^{8}$. When an intense $x$-ray beam strikes a monochromating crystal or a mirrored surface, that surface is heated, causing a distortion, or local thermal bump. Distortions produced by these high power densities, which will occur at unprecedented levels at the APS, would be disastrous to a beam's optical quality. A finite-element-analysis procedure has been implemented to model ${ }^{9}$ the effect of localized high heat loads on optics. Using the Comell machine and beams from the prototype undulator (described earlier). The results of these calculations have been intercompared with performance ${ }^{10}$ to determine the reliability of the finite-element-analysis approach and to optimize designs for optics cooling adequate to the needs of APS.

While the state of the art in optics cooling has been to run water through channels close to the surface of a crystal, Argonne scientists have pioneered the use of liquid metals, particularly gallium, which is about a factor of six more effective as a coolant. At the current stage of development, APS-designed optics can withstand the power densities associated with beams carrying brilliance levels in the $10^{18}$ range. Further optimization of optics cooling systems will be carried out to accommodate the even greater power densities that will come with the $10^{19}$ brilliance level produced by the fully operational APS facility.

\section{Detectors}

The unprecedented brilliance of the $x$-ray beams that will be produced by the APS give rise to the need for new detectors that will at once withstand the intensity of the beams while resolving data at the required high rate of speed. Staff of the APS, in collaboration with researchers at the University of Michigan (U.M.), have developed a radiation-resistant, ultra-fast, two-dimensional electronic detector based on charge-coupled-device (CCD) technology, coupled to specially-designed circuitry. The new CCD will utilize waveform manipulation to capture $x$-ray diffraction images of materials under stress at heretofore unattainable rates.

In an experiment conducted by APS, U.M., and AT\&T Bell Labs at the National Synchrotron Light Source X-16B beamline, the new CCD collected diffraction data with a resolving time of 25 microseconds, the fastest detector performance yet achieved for this application. The new detector has potentiality for 


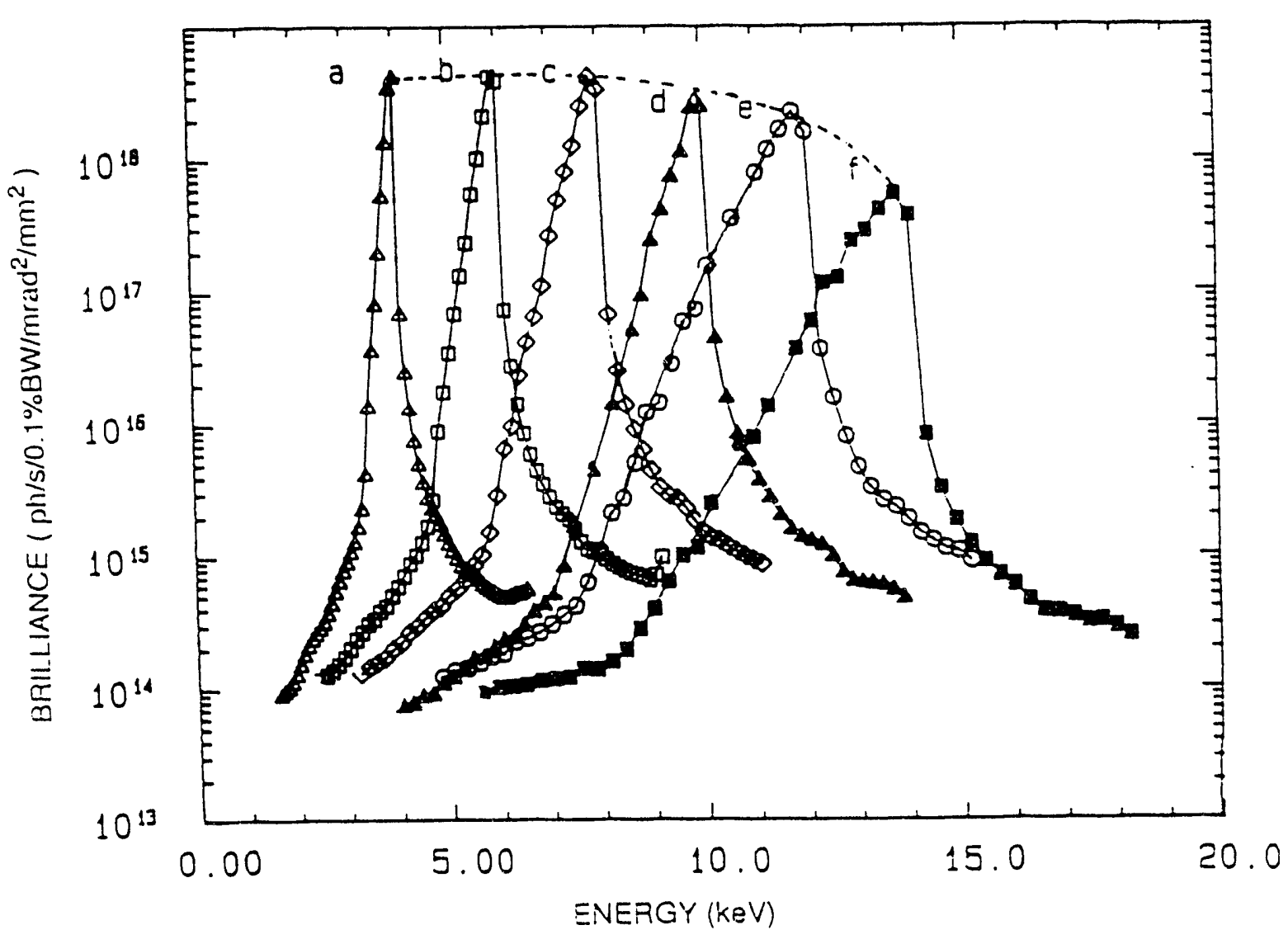

Fig. 3. The angle-integrated brilliance of the fundamental radiation from the undulator $A$ on the APS with $100 \mathrm{~mA}$ at $7 \mathrm{GeV}$. The fundamental peaks at various photon energies are obtained at magnet gap settings of 1) $11.2 \mathrm{~mm}$, b) $13.9 \mathrm{~mm}, \mathrm{c}$ ) $16.5 \mathrm{~mm}$, d) $19.7 \mathrm{~mm}$, e) $24.7 \mathrm{~mm}$, and f) $30.1 \mathrm{~mm}$. These calculations include the phase space dimensions of the positron beam. 


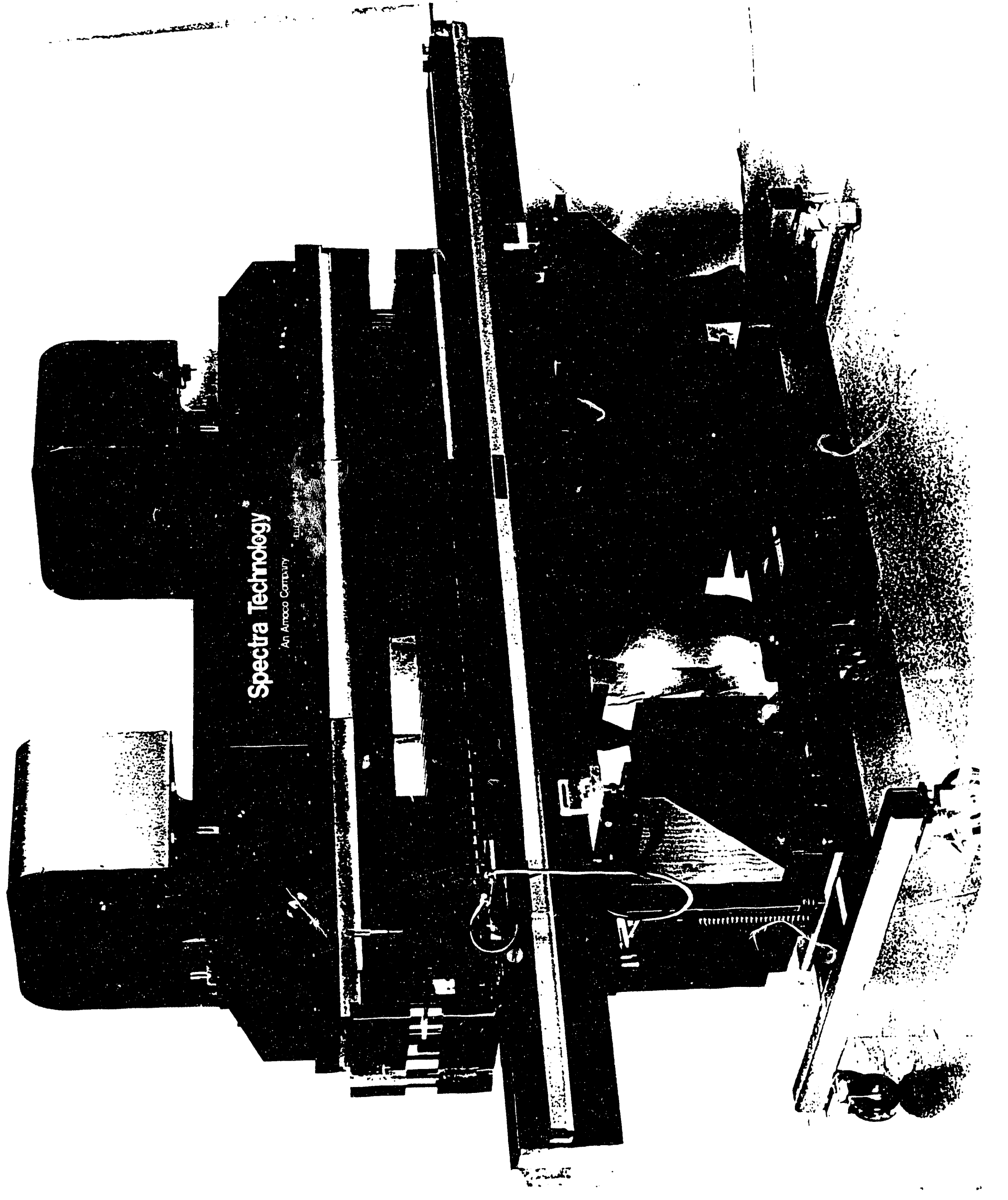


The Advanced Photon Source 7.5-cm undulator, currently under test on the U-5 port of the vacuum ultraviolet ring at the National Synchrotron Light Source, Brookhaven National Laboratory. 
Table I.

APS General-Purpose IDs - Design Parameters

\begin{tabular}{|c|c|c|c|c|}
\hline & \multicolumn{2}{|c|}{ UNDULATORS } & \multicolumn{2}{|c|}{ WIGGLERS } \\
\hline & A. & $B$ & A & $B$ \\
\hline Period (cm) & 3.1 & 2.1 & 15 & 25 \\
\hline Length (cm) & 2.5 & 2.5 & 1.5 & 2.5 \\
\hline \multicolumn{5}{|l|}{ Fundamental: } \\
\hline Min. (keV) & 4.5 & 13 & & \\
\hline Max. (keV) & 14 & 20 & & \\
\hline$E_{C}(k e V)$ & & & 32.6 & 9.8 \\
\hline$K_{\max }$ & 2.5 & 1.1 & 14 & 7 \\
\hline
\end{tabular}

UND. A \& B, WIG. A:

Permanent magnet (Nd-Fe-B) HYBRID DEVICES

WIG. B:

Electromagnet

Bending Magnet Radiation: $E_{C}=19.5 \mathrm{keV}$ 
use in kinetic studies of failure and dislocation strains in metals and high-strength alloys, as well as in the processing of electronic materials necessary for computer and communications technology.

\section{APS USER PRO)(jRAM}

A call for Letters of Intent (LOI) from prospective Collaborative Accus Teams (CAT), due May 1 of this year, has brought a total of 30 LOIs, representing some 300 scientists and engineers from 9 national laboratories, 16 industrial concems. and 47 universities. Review of the LOIs is the responsibility of the APS Proposal Evaluation Board (PEB). Members of the $P E B$ are drawn from the synchrotron radiation community, and the $P E B$ functions independently of $A N L$. This board held its first meeting on May 10-12,1990, and completed preliminary screening of the LOIs. The PEB has submitted its recommendations for CAT candidates to APS management, which has sent letters to all 30 CATs. Of these 30 letters. 22 contain invitations to submit formal proposals (due in December), some suggestions for consolidation of groups to form a CAT or for collaboration between CATs. and comments fiom the PEB. Following approval of formal proposals, a memorandum of understanding will formalize the working relationship between each CAT and Argonne.

The APS will eventually support about 70 beam lines. It is expected to atract more than 1000 users every year from industriai firms, universities. national laboratories, and other institutions.

\section{REFERENCES}

1. "6-GeV Synchrotron X-ray Source Conceptual Design Report". Argonne National Laboratory Report ANL-86-8, Feb. 1986.

2. "Ring Energy Selection and Ex'ra Long Straight Sections for the Advanced Photon Source," Argonne National Laboratory Report ANL-87-14. April 1987.

3. "7-GeV Advanced Photon Source Conceptual Design Report". Argonne National Laboratory Report ANL-87-15, April 1987.

4. "Planning Study for Advanced National Synchrotron-Radiation Facilities". Sandia National Laboratory Report. March 1989.

5. J. Bridges, Y. Cho, E. Crosbie, S. Kramer, R. Kustom. D. Voss. L. Teng. K. Kleman. R. Otte, W. Trzevia, and K. Symon, "Dynamic Aperure Measurement on Aladdin." to be published in the proceedings of the 14th International Conference on High Energy Accelerators. Tsukuba. Japan, Aug. 1989.

6. D. H. Bilderback, B. Batterman, M. Bedzyk, K. Finkelste in, C. Henderson, A. Merlini. W. Schildkamp, Q. Shen. J. White, E. Blum. P.J. Viccaro. D. M. Mills. S. Kim. G.K. Shenoy, K. Robinson, F. James, and J. Slater, "Performance of a hard $x$-ray undulator at CHESS (invited)," Rev. Sci. Instrum. 60 1419-1421. 1989.

7. P. J. Viccaro. G.K. Shenoy, S. Kim, S.D. Bader, "Soft $x$-ray undulator for the L' be:amline at NSLS." Rev. Sci. Instrum. 6n 1813-1815, 1989. 
8. P. J. Viccaro, "Power Distribution from Insertion Device Synchrotron X-ray Sources," Proceedings of the Workshop on High Heat Load X-ray Optics, pp. 5-28, Argonne National Laboratory. Aug. 3-5, 1989, Argonne National Laboratory Report ANL/APS/TM-6, Jan. 1990.

9. J. Chrzas, A. M. Khounsary, D. M. Mills and P. J. Viccaro, "Modeling the Performance of Water and Liquid Gallium Cooled X-ray Optical Components - A Comparison with Experiment," to be published in the proceedings of the 6th National Conference on Synchrotron Radiation Instrumentation, Berkeley, California, Aug. 1989.

10. D. H. Bilderback. B. Batterman, M. Bedzyk, K. Finkelstein, C. Henderson, A. " rlini, W. Schildkamp, Q. Shen. J. White, E. Blum. P. J. Viccaro, D. M. Mills, S. Kin, G. K. Shenoy, K. Robinson, F. James, and J. Slater, "Undulator hea loading studies on $\mathrm{X}$-ray monochromators cooled with liquid gallium," Rev. Sci. Instrum. 60 1973-1976, 1989. 

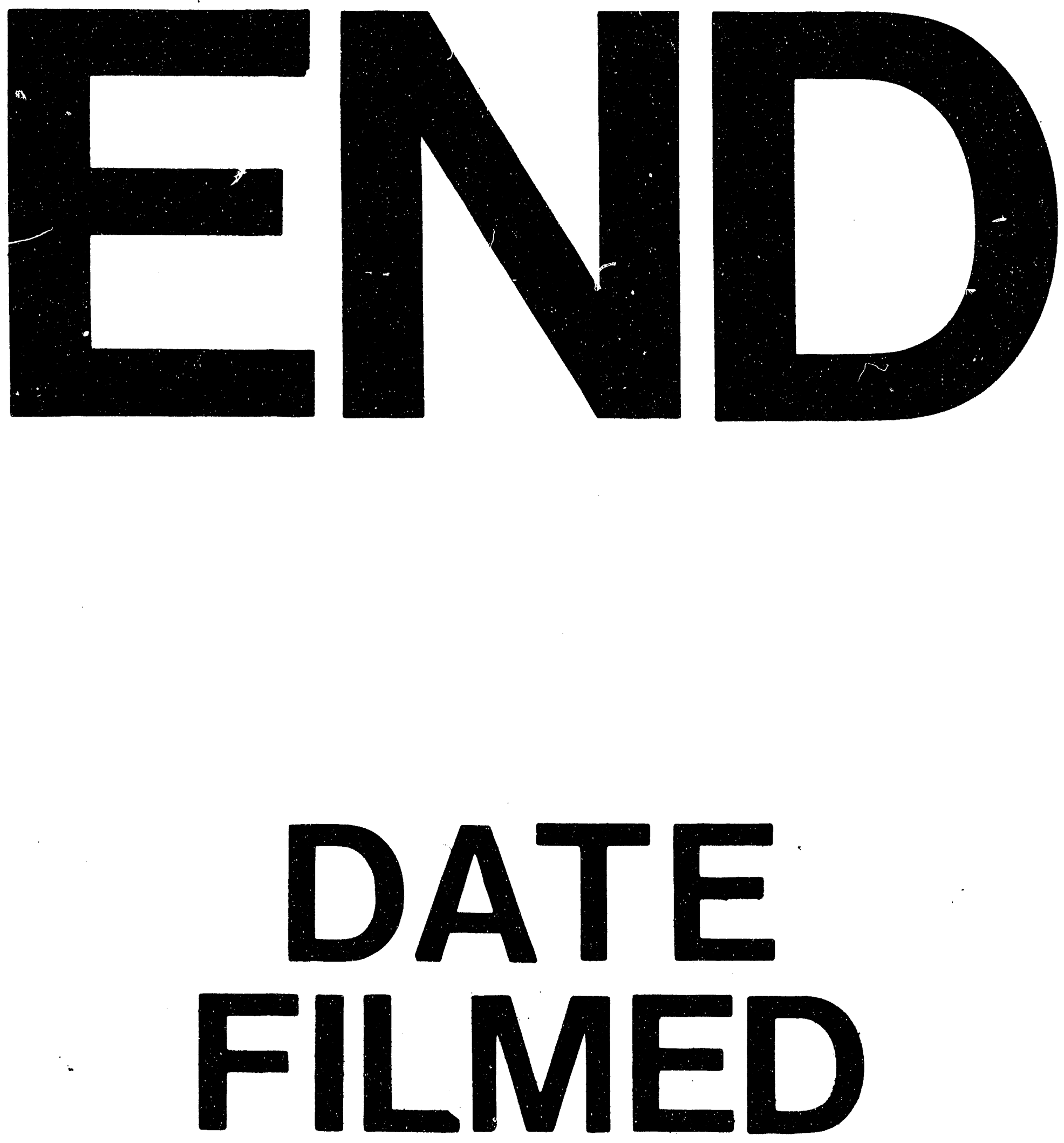

覀

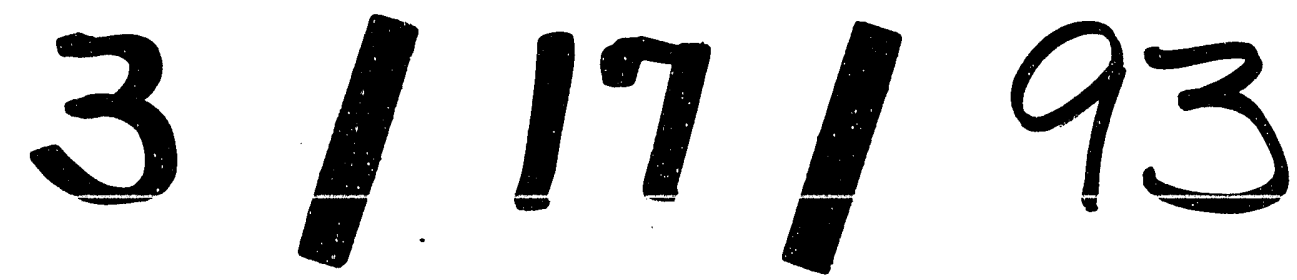


